\title{
Cuerpos abstractos, riesgos concretos: dispositivos clínicos y la salud de las donantes de óvulos en la medicina reproductiva argentina
}

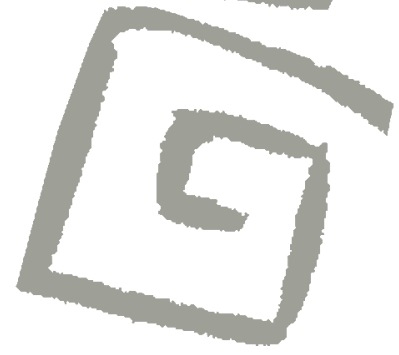

\author{
Abstract bodies, concrete risks: clinical devices and \\ the health of ova donors in Argentine reproductive \\ medicine \\ Lucía Ariza ${ }^{1}$
}

${ }^{1}$ Doctora en Sociología. Investigadora invitada, Instituto de Investigaciones Gino Germani, Universidad de Buenos Aires, Ciudad Autónoma de Buenos Aires, Argentina. $\triangle$ iD
RESUMEN Desde una perspectiva metodológica inspirada por los estudios en ciencia y tecnología, este trabajo analiza dos dispositivos clínicos (estándares bioestadísticos y registros de donación) que se utilizan en la medicina reproductiva argentina con el objetivo de controlar el denominado "riesgo genético" que se originan en el uso de óvulos donados, así como los riesgos para la salud de las mujeres donantes. Al examinar cómo la implementación de criterios de control desatiende la especificidad de la donación de óvulos, el artículo propone que no es la ausencia de criterios y controles clínicos en fertilidad lo que produce el inadecuado control de esos riesgos, sino que es la forma concreta en la cual se implementan tales controles lo que resulta en un potencial perjuicio para la salud de las mujeres donantes.

PALABRAS CLAVES Fertilización In Vitro; Donación de Óvulo; Salud de la Mujer; Argentina.

ABSTRACT Using a methodological perspective grounded in science and technology studies, this article analyzes two sociotechnical devices used in Argentine reproductive medicine (biostatistical measures and donation registries) with the aim of controlling both the so-called "genetic risk" arising from the use of donated ova as well as the health risks to female donors. By examining how the deployment of monitoring criteria disregards the specificity of ova donation, the article suggests that it is not the absence of control measures and clinical criteria that produces an inadequate monitoring of such risks, but rather the concrete ways in which such measures are implemented that results in potential harms to the health of female donors.

KEY WORDS Fertilization In Vitro; Oocyte Donation; Women's Health; Argentina. 


\section{INTRODUCCIÓN}

Como parte de una investigación mayor que examinó el intercambio de óvulos en Argentina ${ }^{\left[{ }^{[a]}\right.}$, este artículo propone reflexionar sobre el cuidado de la salud de las mujeres, especialmente de las mujeres que "donan"[b] óvulos, en el tratamiento médico de fertilidad. Con este objetivo se analiza el uso de dos dispositivos clínicos -las Ilamadas medidas bioestadísticas y los registros de donación- a través de los cuales la medicina reproductiva busca controlar la cantidad de veces que una mujer dona óvulos, con el objeto de prevenir dos riesgos distintos: un incremento en la probabilidad de consanguineidad y un perjuicio para su salud. El artículo argumenta que, sin embargo, estos dispositivos están más centrados en la prevención del riesgo de endogamia que en la reducción del riesgo para la salud de las mujeres donantes, por lo que el perjuicio para la salud de las mujeres donantes no está adecuadamente monitoreado. Paradójicamente, las formas en las cuales se implementan tales dispositivos implican la aparición de nuevos riesgos para la salud de las mujeres.

Pese a los más de treinta años de existencia de la reproducción asistida en Argentina, este campo fue regulado a nivel nacional muy recientemente en junio de 2013, con la Ley 26.862 de Reproducción Médicamente Asistida. Esta legislación garantiza el "acceso integral" a los tratamientos reproductivos a través del sistema público y privado, sin restricciones por orientación sexual, edad o estado civil. Pese a su espíritu democrático y al apoyo que recibió por parte de amplios sectores de la sociedad, principalmente organizaciones de personas con dificultades reproductivas y grupos de activismo lésbico, gay, travesti, transexual, transgénero, bisexual, intersexual y queer (LGTTTBIQ), la ley y su reglamentación definieron solo a grandes rasgos, o evitaron definir, aspectos importantes de la aplicación de las tecnologías reproductivas. Dentro de estos aspectos interesa, en particular, la implementación de bancos de gametos y de un registro central de donantes, lo cual afecta en última instancia la auténtica realización del ímpetu democrático de la ley y menoscaba, de hecho, los derechos de las personas al uso de las tecnologías reproductivas otorgados por la legislación. A su vez, a junio de 2016, la aplicación efectiva de esta ley dista en ciertos aspectos respecto de lo previsto, en la medida en que los sectores sin cobertura médica (obra social o empresa de medicina prepaga) no pueden acceder en muchos sitios a los tratamientos de manera gratuita, como por ejemplo en la Ciudad Autónoma de Buenos Aires. Asimismo, se han reportado dilaciones y negativas por parte de algunos proveedores de salud para la cobertura total de los tratamientos, en especial, en el acceso a estudios diagnósticos, cobertura de la medicación, etc. ${ }^{(3)} \mathrm{Al}$ mismo tiempo, varias responsabilidades conferidas por la ley a organismos nacionales, con el objetivo de dar cumplimiento a lo previsto, no han sido asumidas (como es la mencionada creación de un registro central de donantes). Cabe notar que si bien la reglamentación de la ley estipula que "la donación nunca tendrá carácter lucrativo o comercial", esta se realiza casi exclusivamente a través del intercambio de una remuneración monetaria en todos los centros privados de reproducción asistida, mientras que no existe ningún esquema de donación de gametos que opere bajo un principio de gratuidad en el ámbito púbico.

En el contexto de una marcada institucionalización, especialización y profesionalización como la que está ocurriendo en otros países de la región ${ }^{(4)}$, el desarrollo de la medicina reproductiva argentina se encuentra íntimamente ligado al de una retórica del cuidado de la salud vinculada a la fertilidad y a la mujer en general. Así, por un lado, diversas clínicas argentinas están extendiendo sus servicios estrictamente de procreación hacia una amplia gama de intervenciones que apuntan a cuidar la salud reproductiva y de las mujeres en su conjunto como, por ejemplo, la atención del climaterio, las patologías cervicales y mamarias, las disfunciones del piso pelviano, la inmunología de la reproducción y la preservación de la fertilidad. En ocasiones, los servicios ofrecidos llegan a 
incluir departamentos y prácticas como nutrición, yoga, psicología, dermatología, estética, cirugía plástica, etc., lo que contribuye a una presentación del tratamiento médico de fertilidad como un espacio donde la salud femenina es atendida en su conjunto, rehuyendo al mentado fraccionamiento corporal que fue eje de la temprana crítica feminista a la reproducción asistida ${ }^{(5,6,7)}$.

Por otro lado, en el caso específico de la donación de óvulos, las clínicas de fertilidad suelen destacar el permanente "chequeo" de la salud física y mental de la mujer que dona óvulos ${ }^{(8)}$. Esta insistente retórica en torno a los controles médicos que se realizan en la donante tiene el objetivo, sin embargo, de garantizar a quienes recibirán un óvulo donado que este proviene de una mujer "chequeada", es decir, de una mujer de la que se conocen sus antecedentes reproductivos, en la que se han descartado (hasta cierto punto) enfermedades genéticas, infecciosas o de otro tipo, que pudieran ser transmitidas a la herencia, y sobre la que se pronostica una "buena respuesta" ovárica, dado el conteo de sus folículos. La referencia frecuente al "chequeo de la donante" no puede escindirse, por lo tanto, de las condiciones comerciales en las que se ofrecen tratamientos de reproducción asistida en Argentina, en donde la gran mayoría de los procedimientos son iniciados en clínicas privadas, a altos costos económicos para las y los pacientes. En este contexto, la evaluación médica de la donante, incluso cuando es formulada a través de una retórica del cuidado o de esquemas compensatorios -en los que la donante es en parte resarcida por la donación de sus óvulos a través de la provisión de servicios médicos, como el chequeo de su salud reproductiva ${ }^{(9)}$ - es inevitablemente un aspecto del tratamiento médico entendido en tanto "servicio", y por lo tanto un factor de la composición del costo del tratamiento. Su valor de mercado no puede eludirse.

Este entorno de cuidado de la salud de las pacientes y donantes no quita que la salud de las mujeres, especialmente de las mujeres donantes, no esté en riesgo. En efecto, la participación en calidad de donante en un tratamiento reproductivo supone la exposición de la donante a una serie de riesgos para la salud (no solo) reproductiva. Estos emergen tanto de la extracción de óvulos como evento aislado (su carácter quirúrgico, que implica riesgos relacionados con esta forma de intervención médica: infecciones, complicaciones de la anestesia, sangrado, etc.), como de la extracción de óvulos como evento repetido (complicaciones ligadas a una estimulación ovárica reiterada, que podría vincularse a un riesgo incrementado de contraer algunas formas de cáncer, a una reducción de la fertilidad, y a la aparición del síndrome de hiperestimulación ovárica $\left.{ }^{[\mathrm{cl}}\right)$. Estos riesgos se originan en el involucramiento de la donante en tanto proveedora de trabajo clínico ${ }^{(11)}$, esto es, de un tipo de trabajo corporal en el que la biología de la persona está involucrada ${ }^{[\mathrm{d}]}$.

En este marco, el presente trabajo no solo se pregunta por las previsiones médicas respecto de la salud (reproductiva o de otro tipo) de las mujeres donantes de óvulos antes, durante y después de su participación en un tratamiento de fertilidad. Lo que se indaga también en este caso es cómo aquellas previsiones, disposiciones, protocolos, medidas bioestadísticas o aseveraciones corporativas -respecto de la pertinencia de monitorear los riesgos posibles para la salud de las mujeres, ligados a su configuración como donantes de óvulos- son concretamente realizados en el tratamiento clínico de la fertilidad. Esto es, se apunta a contribuir a un entendimiento del funcionamiento práctico de los dispositivos médicos, en situaciones concretas cotidianas, en este caso ligadas al monitoreo de la salud de las mujeres donantes de óvulos. Así, este artículo indaga en los mecanismos médicos a través de los cuales se previenen los daños a la salud de las mujeres que no solo participan, sino que hacen posible a través de su trabajo clínico la propia existencia de los sistemas de ovodonación.

\section{Los estudios sobre medicina reproductiva en Iberoamérica}

A diferencia de lo ocurrido en el contexto anglosajón, la medicina reproductiva no ha 
sido objeto de un interés académico sustantivo por parte de las disciplinas sociales y humanas en el contexto hispanohablante. Esto tal vez se deba, al menos en Latinoamérica, a la sensación de que existen temas -como la persistente ilegalidad del aborto, la mortalidad materna o el embarazo adolescente- que marcan de manera más candente la agenda de los estudios de salud reproductiva de la mayoría de los países de la región. A continuación, se presentan una serie de trabajos que no pretenden ser una enumeración exhaustiva de la producción en esta área específica de estudios, sino una indicación de los principales temas tratados en torno a la medicina reproductiva, y las posibles áreas de vacancia aún persistentes.

En cuanto a Argentina, país de realización del presente estudio, la investigación en ciencias sociales y humanas sobre tecnologías reproductivas fue marcadamente escasa hasta comienzos de la década de 2000, aunque en años recientes una serie de estudios han ido aportando conocimiento específico sobre el tema. Los trabajos pioneros de Sommer ${ }^{(12,13)} y$ de Luna ${ }^{(14)}$ aportaron luz sobre las asimetrías de género, el carácter invasivo de los tratamientos, la condición experimental de muchas de las técnicas y los dilemas bioéticos representados por estas. En especial, los trabajos de Luna $^{(15,16)}$ han enfatizado las particularidades latinoamericanas de la implementación de técnicas reproductivas, y el contexto de vulnerabilidad que determina su uso. Garay ${ }^{(17)}$ ha contribuido con una reflexión feminista sobre el rol del género en la reproducción asistida; Raspberry ${ }^{(18)}$ produjo un análisis etnográfico de la cuestión ética de las tecnologías reproductivas; y Kemelmajer de Carlucci et al. ${ }^{(19)}$ han aportado al debate legal en relación con las preocupaciones sobre la filiación a raíz del uso de técnicas de procreación. Otros aspectos legales han sido examinados por Calise ${ }^{(20)}$, quien estudió la situación de los embriones sobrantes, y por Lloveras y Sapena ${ }^{(21)}$, quienes prestaron atención a la posible regulación del diagnóstico genético preimplantatorio. Por su parte, Cuberli et al. ${ }^{(22)}$ han puesto en tensión las tecnologías reproductivas con otras prácticas que involucran decisiones reproductivas como el aborto y el test de VIH; Straw y Petracci ${ }^{(23)}$ realizaron análisis comparativos del uso de las tecnologías reproductivas en sectores medios y populares de la Ciudad Autónoma de Buenos Aires; Gemetro y Bacin ${ }^{(24)}$ y Ariza y Libson ${ }^{(25)}$ contribuyeron al estudio sobre el uso de la medicina reproductiva por parte de mujeres heterosexuales y lesbianas. Ariza ${ }^{(26)}$ estudió las razones para realizar o no tratamiento reproductivo en mujeres con dificultades reproductivas, las prácticas médicas y la construcción de ideas en torno a lo natural en la donación de gametos ${ }^{(27)}$, y proveyó una discusión sobre el activismo por la inclusión de la reproducción asistida dentro del Plan Médico Obligatorio ${ }^{(28)}$.

En cuanto al resto de los países, en la producción española se destacan la contribución sobre los aspectos legales de la regulación de las tecnologías reproductivas de Puerto $^{(29)}$; el trabajo de Bestard ${ }^{(30)}$ sobre la co-producción entre lo social y lo biológico en las tecnologías reproductivas y las repercusiones para el parentesco; el estudio sobre la filiación no biológica de Jarufe Contreras( ${ }^{(31)}$; la contribución sobre turismo reproductivo de Farnós Amorós $^{(32) ;}$ los aportes sobre psicología de la reproducción de Rosset et al. ${ }^{(33)}$, y las tensiones entre reapropiaciones subversivas y repetición de patrones de género tradicionales en el uso de tecnologías reproductivas en España, analizadas por Fernández Jimeno ${ }^{(34)}$. En cuanto a los países latinoamericanos, resaltan el trabajo de Herrera et al. ${ }^{(35)}$ sobre reproducción asistida y opinión pública en Chile; las reflexiones de diversos autores sobre (bio)ética de la reproducción asistida y aspectos legales ${ }^{(36,37,38,39,40,41,42)}$; las contribuciones bioéticas y legales sobre el derecho a la identidad y la filiación de personas nacidas por donación de gametos en tecnologías reproductivas ${ }^{(43,44,45,46)}$; el análisis de los significados del consentimiento en la medicina reproductiva de Albertoni Vazzaco et al. ${ }^{(47)}$; el estudio etnográfico del estatus del embrión en Ecuador de Roberts ${ }^{(48)}$; y los aportes para comprender la búsqueda reproductiva desde la psicología y el psicoanálisis como los de Escalante Barboza ${ }^{(49)}$ y de Lanius y Souza ${ }^{(50)}$. 
Existe un estudio empírico venezolano de Romero Márquez ${ }^{(51)}$ acerca de las representaciones sociales sobre la reproducción asistida entre un grupo de personas que accederían potencialmente a ella.

En conjunto, lo anterior indica que en Iberoamérica los estudios sobre reproducción asistida han sido, en general, de corte teórico y normativo, con escasísimos ejemplos de estudios de caso empíricos y formulación de problemas de investigación localizados. La producción en este terreno ha tendido a centrarse en las problemáticas bioéticas y legales, dejando de lado, en general, el examen de las experiencias de los y las usuarias de las técnicas, así como de las prácticas médicas. Ni la sociología, ni la antropología de la medicina y la salud, ni los estudios sociales de la ciencia y la técnica han incursionado, en general, en análisis pormenorizados del quehacer médico, ni han prestado atención a la interacción en el propio quehacer entre agentes humanos y no humanos. Es notable, asimismo, la total ausencia de investigaciones centradas en la donación de gametos, lo que incluye la falta de estudios sobre los potenciales riesgos para la salud de las mujeres involucradas en la donación de ovocitos de las tecnologías reproductivas, como el que es abordado en este trabajo. Vale destacar, finalmente, que cuando se ha abordado la cuestión de la filiación no biológica en el caso de la reproducción asistida, el enfoque ha sido casi exclusivamente en los aspectos legales y los principios éticos involucrados, sin incorporar análisis del uso de dispositivos sociotécnicos en la gestión de los riesgos involucrados.

\section{METODOLOGÍA}

La investigación de la que se desprende este artículo adoptó una perspectiva metodológica basada en los estudios en ciencia y tecnología (science and technology studies). Puesto de una manera simple, estos estudios buscan conocer las formas contemporáneas de hacer ciencia y tecnología ${ }^{(52)}$, de proveer un "conocimiento inclusivo de los orígenes, dinámicas y consecuencias" de aquellas ${ }^{(53 \text { p.1). }}$ Así, aunque actualmente se trata de un enfoque vasto y multifacético, puede sintetizarse que el interés de los estudios en ciencia y tecnología es conocer las prácticas en las que se produce conocimiento científico, las conexiones entre la ciencia, la tecnología, el Estado, la economía, la industria o el derecho, así como las maneras en las que los diferentes públicos participan en la formación de objetivos científicos y evalúan sus resultados ${ }^{(53)}$. Los estudios en ciencia y tecnología se caracterizan asimismo por una aversión a las generalizaciones sobre los modos de funcionamiento del conocimiento o la ciencia, precisamente porque buscan estudiar las maneras concretas, situadas, locales del hacer ciencia/s y generar conocimiento/s $\mathrm{s}^{(54)}$.

Respecto de la historia de los estudios en ciencia y tecnología, estos tienen sus antecedentes en la filosofía y la sociología del conocimiento científico. Allí fueron muy importantes los trabajos de Karl Popper, Robert Merton, Ludwik Fleck y Thomas Kuhn, entre otros. De un modo genérico, estos autores buscaban, por un lado, indagar en la viabilidad y operatoria del conocimiento científico (Popper, Fleck y Kuhn) y, por otro, conocer cuáles eran las condiciones sociales del conocimiento, por ejemplo, cuáles eran las determinaciones políticas de los programas de investigación científica, o cuáles eran las normas y las feroces competencias internas del campo científico (en Merton). En la agenda mertoniana se trataba, entonces, en gran medida, de una búsqueda de explicaciones "externas" sobre el avance de la ciencia, mientras que los trabajos de Popper, Fleck y Kuhn anticiparon el involucramiento de la filosofía y la sociología con la materia de la ciencia en sí. Con estas influencias, en la década de 1970 comenzó a desarrollarse un nuevo campo de estudios, la "sociología del conocimiento científico", que no buscaba ya comprender las condiciones sociales de producción de conocimiento científico, sino analizar propiamente el contenido de la ciencia: esto es, cómo es que el juego de teorías que explican fenómenos va progresivamente 
produciendo conocimiento sobre estos a través de la construcción de hechos científicos, de una manera no teleológica. Un nuevo campo se abría así a los estudios de las ciencias humanas y sociales interesadas en el estudio de la ciencia desde una perspectiva "internista", esto es, en el estudio de la producción de hechos científicos.

Un hito clave en esta nueva apertura fue la publicación de La vida en el laboratorio. La construcción de hechos científicos, de Bruno Latour ${ }^{(55)}$. Este libro inauguró una de las tradiciones más importantes dentro de los estudios en ciencia y tecnología, aquella de los estudios de laboratorio, a la vez que es uno de los trabajos fundantes de la teoría del actor-red. Tanto los estudios en ciencia y tecnología como la teoría del actor-red comparten aspectos esenciales que los distinguen de otras ramas del quehacer en las ciencias sociales y humanas, entre ellos: a) las ideas sobre la relatividad de las verdades científicas (dado que todo avance en ciencia es resultado de un complejo sistema de interacciones específicas entre elementos contingentemente localizados dentro de una misma disciplina, problema de investigación o lugar de trabajo, todo hecho científico puede ser únicamente situado, contextual, pero, como tal, verdadero); b) la idea de que el conocimiento científico es real; y c) de que el conocimiento científico es construido.

Durante la década de 1990 y a raíz de una serie de eventos entre los que se destaca el "affair Sokal"[e], esta piedra de toque de los estudios en ciencia y tecnología y de la teoría del actor-red (la concepción sobre el carácter relativo, construido y real del conocimiento científico) fue radicalizada, al producirse un fuerte contraste con las visiones posmodernas sobre la ausencia de objetividad, realidad o materialidad del mundo y del proyecto científico que pretende conocerlo, así como sobre su irredimible determinación por parte de las "condiciones sociales" de su producción.

Como se dijo, una corriente importante dentro de los estudios en ciencia y tecnología es la teoría del actor-red, en la cual se inscribe este estudio. Esta corriente se identifica originalmente con el trabajo de tres autores:
Bruno Latour, Michel Callon y John Law, y fue desarrollada a la par que los estudios de caso, especialmente estudios de prácticas de laboratorio, o estudios de actividades económicas como los de Callon en la ciudad francesa de St. Brieuc Bay, entre otros ${ }^{(56)}$. Aunque a menudo se concede la dificultad de describir de una forma totalizada los aspectos centrales de la teoría, un elemento clave es la aproximación al estudio de la ciencia y la tecnología "en proceso" ("in the making"), esto es, el estudio de los actores que hacen ciencia y los lugares donde se hace ciencia ${ }^{(57)}$. Otras cuestiones importantes son el imperativo latouriano de "seguir a los actores" (que para la teoría del actor-red no son solo actores humanos) que lentamente van construyendo la "red" a través de la cual se hace ciencia y tecnología; y “abrir la caja negra"(57), es decir, observar los micro-procesos a través de los cuales los hechos científicos y tecnológicos son producidos. En esta exploración, Law ${ }^{(56)}$ propone que la teoría del actor-red debe ser entendida como una "semiótica material", y toma la idea de la semiótica de que las entidades solo se definen unas en relación con otras y la aplica a todos los materiales, no solo los lingüísticos. La teoría del actor-red asume que ninguna entidad (actor) es algo por sí misma, sino más bien algo que es performatizado (actuado, repetido, construido) a través de una red, mientras que desde luego cualquier red es el resultado de la agencia de los/as actores. El enfoque de la teoría del actor-red es resumido por Law de la siguiente manera:

La teoría del actor-red es una familia diversa de herramientas material-semióticas, sensibilidades y métodos de análisis que tratan todo [lo comprendido] en los mundos sociales y naturales como efectos continuamente generados de las redes de relaciones en los que aquellos están localizados. [La teoría del actor-red] asume que nada tiene realidad o forma por fuera de la instanciación de esas relaciones. Sus estudios exploran y caracterizan las redes y prácticas que las acarrean. Al igual que otros 
enfoques material-semióticos, la teoría del actor-red describe por lo tanto la producción de relaciones material y discursivamente heterogéneas que producen y reorganizan a todo tipo de actores, incluyendo objetos, sujetos, seres humanos, máquinas, animales, "naturaleza", ideas, organizaciones, inequidades, escalas y tamaños, y arreglos geográficos. ${ }^{(56}$ p.2) ${\text { (Traducción de la autora }{ }^{[f]}}^{[\mathrm{f}}$

Tomando los aportes de los estudios en ciencia y tecnología y de la teoría del actor-red, este estudio buscó no dar por sentado, ni privilegiar epistemológicamente, la acción humana en las ontologías clínicas que fueron estudiadas. Por el contrario, se partió de la base de que el espacio médico es un lugar habitado tanto por humanos como por no humanos (como son el equipamiento médico, los dispositivos administrativos, las condiciones edilicias, los contratos legales, el material publicitario, las estadísticas y protocolos médicos, los óvulos y el esperma, etc.), así como por entidades cuyo estatus humano es todavía objeto de disputa o permanece en suspenso en las sociedades latinoamericanas, como los embriones. Bruno Latour ha dicho, por ejemplo:

...ninguna ciencia de lo social puede iniciarse siquiera si no se explora primero la cuestión de quién y qué participa en la acción, aunque signifique permitir que se incorporen elementos que, a falta de mejor término, podríamos Ilamar no-humanos [...] en cuanto [a los objetos] se los libera del encantamiento, comienzan a temblar, estirarse, murmurar; comienzan a pulular en todas las direcciones, sacudiendo a los actores humanos, despertándolos de su sueño dogmático. ${ }^{(58 \text { p.107-109) }}$

A su vez, y en concordancia con lo anterior, los estudios en ciencia y tecnología y de la teoría del actor-red han sido característicos por su énfasis en el examen de los aspectos materiales y concretos de las realidades empíricas estudiadas, rehuyendo a las síntesis totalizadoras sobre "la técnica" o la expectativa de que una determinada tecnología funcione de la misma manera en varios lugares diferentes. Como se referenció más arriba, los estudios en ciencia y tecnología y la teoría del actor-red han debatido profundamente con las corrientes posestructuralistas que privilegian la idea de que cualquier objeto, entidad, problema, identidad, proyecto político, hecho científico, etc., es el resultado de prácticas lingüísticas que construyen sentido para las prácticas humanas. Inspirados en Foucault ${ }^{(59)}$, los estudios en ciencia y tecnología y la teoría del actor-red entienden que la construcción social nunca puede escindirse de los dispositivos materiales a través de los cuales es hecha, y no puede reducirse nunca al dominio de la palabra. Por ello, antes que perpetuar las corrientes más discursivas del constructivismo social y de los abordajes cualitativos, en general predominantemente preocupados con el decir (más que el hacer) de las personas estudiadas, los estudios en ciencia y tecnología han destacado que una aproximación solo con base en las ideas, cosmovisiones o ideologías corre el riesgo de dejar de lado aspectos centrales de los problemas abordados. Por ejemplo, Annemarie Mol ha indicado que:

En lugar de estudiar estos temas extrayendo lo que los doctores saben o lo que ocurre con el autoconocimiento de los pacientes, he analizado el conocimiento incorporado en prácticas [...] [que] no reside solo en los sujetos, sino también en los edificios, cuchillos, tinturas, escritorios [...] la organización material de las prácticas médicas da forma a la realidad de la enfermedad. ${ }^{(60}$ p.48) (Traducción de la autora) ${ }^{[\mathrm{g}]}$

Durante 2008 y 2009, antes de la sanción de la Ley de Reproducción Médicamente Asistida, se realizaron 32 entrevistas con profesionales de diversas especialidades médicas que se desempeñaban en clínicas de fertilidad. Dado el carácter cerrado y, hasta cierto punto, de difícil acceso del campo estudiado, la mayoría de los/as participantes fueron reclutados/as a través de la utilización de la técnica de muestreo comúnmente 
denominada "bola de nieve". Sin embargo, algunos/as entrevistados/as fueron contactados/as de manera directa por la investigadora a través de correo electrónico o teléfonos institucionales y públicamente accesibles. Durante las entrevistas, los temas abordados versaron sobre la actividad cotidiana en la atención clínica, en general incluyendo algunas preguntas generales sobre el funcionamiento del centro de fertilidad, y preguntas específicas relacionadas con la especialidad médica de la persona entrevistada. Los y las participantes provenían de las siguientes especialidades: ginecología, biología y bioquímica, genética, psicología y psicoanálisis, endoscopía, endocrinología y clínica. Para la selección de las especialidades se tuvo en cuenta su participación en las distintas áreas de intervención del tratamiento médico. Para la selección de los/as profesionales se estableció que estos se desempeñaran o se hubieran desempeñado en el marco de un centro de reproducción, por lo que quedaron excluidos los profesionales que trabajaran de forma autónoma. Dadas las dificultades de acceso al campo, los únicos criterios de inclusión para la selección de las clínicas de fertilidad fueron que se tratara de establecimientos que hubieran pertenecido al sector con una antigüedad no menor a un año, y que hubieran realizado tratamientos exitosos durante el mismo período.

La investigación también incluyó la consulta con científicos/as que trabajaban en el área de investigación básica en fertilidad. Todas las personas entrevistadas firmaron un consentimiento informado en el que aceptaban participar de la investigación luego de haber recibido información sobre sus objetivos y el destino de la información recabada. Todos los datos y la identidad de las personas entrevistadas fueron mantenidos en confidencialidad. En esta investigación se realizaron entrevistas en siete clínicas de fertilidad de la Ciudad Autónoma de Buenos Aires. La investigación fue aprobada por el Comité de Ética del Department of Sociology de Goldsmiths, University of London.

A lo largo de la investigación, se recolectó también una serie de materiales (formularios de consentimiento informado, hojas informativas, folletos, propuestas de legislación, diagramas, formularios de evaluación, etc.) cuya circulación y agenciamiento conjunto con los humanos fue analizado como parte de la formación de redes y de la performatización material de ideas en torno a la naturaleza y la procreación ${ }^{(2,27,61,62)}$.

Respecto de la utilización de la entrevista, dispositivo principalmente lingüístico, como método de acceso a las ontologías clínicas estudiadas, se tuvo el cuidado de seguir la experiencia de $\mathrm{Mol}^{(60)}$ sobre la aplicación de este instrumento de recolección de datos. En efecto, Mol sugiere que solo en una perspectiva que reifica la diferencia entre cuerpo y mente, enfermedad y sentimientos sobre la enfermedad, la entrevista puede concebirse como un dispositivo que permite acceder únicamente al sentido de lo que le pasa al cuerpo (dejando de lado la comprensión del cuerpo per se). Por el contrario, alejándose de la frecuente renuencia de los/ as cientistas sociales a estudiar el cuerpo, confinándose simplemente al estudio de los sentidos e interpretaciones que las personas dan al cuerpo, Mol propone que la entrevista debe aplicarse para preguntar a los médicos y pacientes "sobre lo que hacen y sobre los eventos que les suceden, antes que sobre su pensamiento" ${ }^{\prime \prime 60} \mathrm{p}$. 16)[h]. Esta manera de utilizar la entrevista permite desentrañar (mejor) el conocimiento médico, lo que "requiere una investigación de los procedimientos clínicos y de los aparatos antes que de las mentes y de las operaciones cognitivas de los médicos" ${ }^{\prime \prime 60 ~ p .16)[i] . ~ P o r ~ l o ~ t a n t o, ~ l a s ~ e n t r e v i s t a s ~}$ buscaron establecer cuáles eran las actividades de los/as profesionales entrevistados/ as en el tratamiento clínico de fertilidad, y apuntaron a comprender de qué maneras estos interactuaban con los dispositivos médicos y otras "practicalidades"(60) de la vida cotidiana en la medicina reproductiva, antes que conocer los "sentidos profundos", los "sistemas de pensamiento" y las "interpretaciones" y "sentidos" que los/as entrevistados/ as daban a su quehacer diario.

Una vez realizadas las entrevistas, estas fueron analizadas buscando responder a los 
interrogantes de esta investigación respecto de la figuración de ideas y prácticas sobre la naturaleza en el intercambio de gametos de la reproducción asistida en Argentina. Se prestó especial atención a encontrar, analizar y comprender las maneras en las cuales los/ as participantes humanos entrelazan sus acciones con las de aquellos dispositivos médicos, buscando conocer de qué manera las realidades médicas estudiadas están necesariamente compuestas por elementos semióticos y materiales, humanos y no humanos. En resultados parciales de estos análisis ${ }^{(2,27,62)}$, se discute la producción de coherencia racial y de diversidad biológica como parte de la instanciación de ideas y prácticas en torno a qué es naturaleza en la reproducción asistida.

Como correlato de este trabajo, se ha abordado en sucesivas producciones el análisis de temas emergentes de la recolección de datos realizada, como la presentada en este artículo. En este sentido, si bien no fue un objetivo explícito de la investigación comprender cómo era abordada la salud de las mujeres en la práctica médica de fertilidad, la información recogida permitió establecer un área de problematización en torno al cuidado de la salud de las mujeres, especialmente de las mujeres donantes. Para el análisis de esta dimensión, se procedió de forma semejante a la utilizada en producciones previas, es decir, prestando especial atención a cómo puede considerarse que el cuidado (o no) que se realiza de la salud de las mujeres es al menos en parte el resultado de la interacción entre agentes humanos y dispositivos biomédicos, mientras que no puede ser (solo) atribuida a ideas, ideologías o formas de pensamiento respecto de la temática. En efecto, el examen que se presenta a continuación muestra que si bien existe una suscripción discursiva de la importancia de preservar la salud de las mujeres a través de las prácticas de la medicina reproductiva, la consideración de las prácticas concretas en las cuales tal suscripción debería manifestarse, así como de las interacciones entre sujetos y objetos de la práctica médica, muestra un panorama distinto al esperado; esto es, una cierta des-consideración por la salud de las mujeres intervinientes.
Con base en los estudios en ciencia y tecnología, en la teoría del actor-red y en las entrevistas realizadas, en lo sucesivo se analiza el rol de dos dispositivos médicos específicos, las medidas bioestadísticas y los registros clínicos de donación, como mecanismos de control de la salud de las mujeres donantes en el tratamiento médico de fertilidad. Los mecanismos de monitoreo analizados son entendidos como sociotécnicos, en la medida de que presuponen la acción humana, aunque no son irremisiblemente reductibles a ella (esto es, demuestran una cierta autonomía en su operatoria, pero esta no implica un deslinde total de la agencia humana). Estos dispositivos contribuyen materialmente a la organización de la realidad clínico-científica, que debe ser entendida en consecuencia como producida por prácticas materiales, corporales y sociotécnicas, entre otras. Tal indagación tiene, por lo tanto, el objetivo de mostrar el considerable margen de acción que aquellos adquieren en el tratamiento médico de fertilidad en tanto entidades no-humanas, y de ejemplificar una perspectiva atenta a la materialidad y las "practicalidades"(60) de los procedimientos médicos.

\section{MEDIDAS BIOESTADÍSTICAS}

\section{El "riesgo genético"}

La biología moderna se funda en una serie de principios, entre los cuales se encuentra la ley de la variabilidad. La teoría de la "selección natural" formulada por Darwinin ${ }^{(63)}$, según la cual se explica la prevalencia o relativa ausencia de ciertos rasgos biológicos en una población, tiene como prerrequisito central las diferencias en la constitución genética de los individuos de una población. Tal variación posibilita la "adaptación al ambiente", en tanto la adquisición de nuevos rasgos (por mutación o cruza con otra afluencia poblacional, entre otras razones) garantiza la renovación genética que torna a los individuos y poblaciones capaces de afrontar cambios en las condiciones de 
vida, y así superar el peligro de extinción. La diversidad genética es, por lo tanto, un principio entronizado en la gran narrativa biológica moderna. Según esta narrativa, aquellos individuos cuyos rasgos mejor los predisponen a la supervivencia en determinadas condiciones ambientales históricas son aquellos que más se reproducirán y más distribuirán sus genes en una determinada población. La evolución de las poblaciones es resultado de la dinámica entre rasgos más y menos propiciadores de la relación con el ambiente la que, a su vez, es posible gracias a la variabilidad entre individuos.

La medicina reproductiva no es ajena a estas ideas; por el contrario, son centrales en la organización de los servicios médicos que se proveen a personas que no pueden concebir con sus propios gametos. Guiados por la imposición de no contravenir las formas intrínsecas de organización de la vida, los servicios médicos para la fertilidad no solo no se alejan, sino que se proponen explícitamente reproducir lo que se toma por la normatividad natural(1). Así, las referencias a la necesidad de garantizar la variabilidad genética en el caso del uso de gametos donados, y el concomitante rechazo a violentar las formas en las cuales opera espontáneamente la selección natural, son extremadamente frecuentes en las prácticas semiótico-materiales de la práctica médica de fertilidad.

¿Pero dónde se funda esta insistencia? En la preocupación médica de que el uso de gametos provenientes de los/as mismos/ as donantes incremente la probabilidad de que dos personas que comparten ancestros "se conozcan y se casen" (Ginecólogo 4), y generen una reducción en el acervo genético disponible. Esto es, si los y las donantes de óvulos y esperma para uso en tratamientos de fertilidad provienen -como es en cierta medida en Argentina- de un grupo reducido con escasa renovación que hace que donen "siempre los mismos", existe la posibilidad de que las personas procreadas a través de estos gametos reproduzcan juntos en un futuro, reduciendo así la diversidad poblacional. La ratificación de estos riesgos debilitaría la orientación institucional de la medicina de la fertilidad como un servicio que imita $-y$ no contradice- la pretendida norma natural de la variabilidad, por lo que estos riesgos son administrados a través del uso de dos dispositivos sociotécnicos -medidas bioestadísticas y registros clínicos de donación- orientados a una disminución del riesgo. En este apartado se indaga el uso del primero de estos mecanismos, las medidas bioestadísticas usadas con el fin de controlar la probabilidad de endogamia $y$, secundariamente, el riesgo para la salud de las mujeres.

Muchos/as profesionales se refieren, frecuentemente, al "riesgo de consanguineidad" o "riesgo genético" para explicar la razonabilidad del uso de límites a la cantidad de veces que se le permite donar a una donante de óvulos. Estos límites, que algunos profesionales denominan "medidas bioestadísticas", se utilizan con el objetivo de reducir la probabilidad del encuentro entre personas con los mismos ancestros. Las medidas utilizadas se expresan, en general, en forma de ratios que estipulan una cantidad de donaciones (o de embarazos o, en menor medida, de nacimientos) para una población dada. Ejemplos de estas medidas son "25 embarazos cada 700.000 habitantes", "1 nacimiento por millón de habitantes", etc. La definición de estos ratios ${ }^{[i]}$ es de orden matemático e implica un cálculo de la probabilidad de "encuentro" de dos "medio hermanos", como lo muestra la cita que sigue:

Nosotros en realidad el cálculo es que, ¿Cómo era...? Era 20 cada millón, esta es la cifra aceptada, 20 por millón es lo mismo que decir 1 cada 100.000, o sea esto es 1 cada 50.000. ¿Qué es lo que importa?, digamos ipor qué no pueden tener más nacidos? Si yo utilizo 20 embarazos para una población de 1 millón, esto quiere decir [...] [que] el día de mañana la posibilidad de encuentro de 2 medios hermanos es 1 en 50.000 por 1 en 50.000. O sea 5 por 5, 25 y después te queda acá son 4 ceros, y acá otros 4 ceros. ¿Cuánto te da esto? Mirá vos, 2.500.000.000. 1 en 2 mil quinientos millones. O sea que si yo me pongo esta 
cifra, la probabilidad es bajísima. En la medida de que yo aumente, esto va disminuyendo y puede que se encuentren, dos medios hermanos (Genetista 1)

Como se ve en esta cita, el cálculo de un ratio que permite regular el riesgo de encuentro de personas con los mismos ancestros tiene un carácter abstracto. Su establecimiento no se deriva en muchos casos de estudios concretos (geográficos, de historia poblacional o sanitarios) que permitan, en función del conocimiento de aspectos relevantes de una población real dada (por ejemplo, la densidad o el grado de parentesco entre sus habitantes) establecer un riesgo de consanguineidad apropiado. Sin embargo, como se mostrará más abajo, esta medida abstracta es utilizada para regular los riesgos para los cuerpos concretos de las mujeres, de una forma que abre preguntas respecto de su efectividad.

Este carácter abstracto de las medidas bioestadísticas utilizadas puede observarse también en el uso de guías médicas que proponen un límite a la cantidad de donaciones que se aceptarán de una donante. Las guías más citadas son, en efecto, las 2008 Guidelines for gamete and embryo donation: A practice committee report, publicadas conjuntamente por la American Society for Reproductive Medicine (ASRM) y la Society for Assisted Reproductive Technology (SART), dos organizaciones estadounidenses que nuclean a profesionales del campo de la medicina reproductiva. Estas guías, publicadas en 2008, son de referencia permanente entre los profesionales de la reproducción asistida de Buenos Aires, tal como fue testimoniado en las entrevistas realizadas. En ellas se provee, solo para el caso de la donación de esperma, una recomendación no vinculante respecto de la cantidad adecuada de veces que un donante puede donar material reproductivo:

Es difícil proveer una medida precisa del número de veces que un donante será usado ya que uno debe tomar en consideración la población base de la cual el donante es seleccionado, y el área geográfica que será servida por cada donante. Se ha sugerido que en una población de 800.000, limitar [las donaciones de] un donante a 25 nacimientos evitaría cualquier incremento significativo del riesgo de concepción consanguínea inadvertida. Esta sugerencia puede precisar modificación si la población que usa inseminación de donante representa un subgrupo aislado o si los especímenes están distribuidos a lo largo de una amplia área geográfica. ${ }^{(64)}$ (Traducción de la autora) ${ }^{[k]}$.

Esta recomendación apunta a regular la cantidad de veces que se debería donar gametos en una población determinada, esto es, la población del país en el que las recomendaciones fueron producidas (EE.UU.). Sin embargo, y pese a estas precauciones, al carecer de una medida que -teniendo en cuenta aspectos del contexto local (como la distribución y densidad geográfica, historia poblacional, realidad sanitaria o grados de parentesco entre los habitantes, etc.)- funcione adecuadamente en este contexto, los profesionales argentinos utilizan de forma descontextualizada la medida sugerida para el país del norte. Esta elisión de las condiciones específicas que habilitan el uso de la medida en EE.UU. (por ejemplo, de los estudios epidemiológicos realizados que probarían que la medida dada es adecuada para prevenir el riesgo de endogamia) erosiona el carácter concreto con que la medida es utilizada en EE.UU., es decir, el hecho de que su recomendación tiene en cuenta información local. Así, las clínicas de fertilidad argentinas utilizan de forma inespecífica la medida obtenida, basada en criterios poblacionales específicos en el país del norte, en tanto esta no se ha derivado teniendo en cuenta las características de la población argentina en la que será aplicada. Esto no solo indica el carácter menos concreto o menos específico del uso de la medida en Argentina, cuando es trasladada al contexto local sin mediación desde su formulación para el caso de EE.UU., sino también la irrelevancia de la pregunta por la significación del contexto en la traslación o 
aplicación clínica de medidas formuladas en otros lugares.

A este proceso de abstracción o de supresión de las bases empíricas que sustentan el uso de una medida determinada, se suma el hecho de que las recomendaciones estadounidenses son solo para el caso de la donación de esperma. En este sentido, su uso para la donación de óvulos, tal como se hace en Argentina, supone un nuevo proceso de abstracción, esto es, una abstracción del sexo para el que deben funcionar, que la transforma en una medida utilizada con independencia del sexo, una medida genérica (aplicable de manera disociable de su contextualidad) pero des-sexualizada. De esta manera, los riesgos específicos de la donación de óvulos (su carácter quirúrgico, su dependencia de una estimulación hormonal, entre otros) son igualmente des-corporizados, obliterando la pregunta por el efecto de un número dado de donaciones (por ejemplo, 25) en los cuerpos de las mujeres que donan.

\section{El riesgo para la donante}

Por otro lado, al indagar sobre el uso de las medidas que limitan la cantidad de donaciones en nombre del riesgo genético, emergió entre algunos/as de los/as entrevistados/as otro tipo de explicaciones -menos explícitas y menos frecuentes- respecto de la necesidad de utilizarlas. En efecto, especialmente las entrevistadas mujeres argumentaron que, además del riesgo posible de consanguineidad, la limitación sobre la cantidad de donaciones se basaba en la necesidad de preservar la salud de las mujeres que donan óvulos. Una entrevistada indicó, por ejemplo, que el número que limita la cantidad de veces que una donante puede donar:

...está relacionado con el riesgo de cáncer de ovario y con el riesgo de disminución de la reserva ovárica para esa paciente que el día de mañana quizás es joven y quiere tener más hijos. En general se dice que no hay relación con la alteración de la fertilidad ni relación con cáncer [...] pero seis es como un número límite, porque imaginate que es una poliovulación que están haciendo cada tres meses, y para el ovario eso es mucho, y para el cuerpo en sí es mucho. (Ginecóloga 2)

Este testimonio, de una profesional mujer, es indicativo de algunas de las preocupaciones que atraviesan el campo reproductivo y que son presentadas por algunas de sus profesionales como argumentos para justificar la organización de los servicios. En este caso, la entrevistada se refiere a la posibilidad de que la estimulación ovárica hormonal que se realiza a las donantes de óvulos afecte su salud, en especial en lo relativo al riesgo de cáncer o de una disminución de su fertilidad. La profesional aclara que si bien no existe un reconocimiento médico de este riesgo ${ }^{[\Pi]}$, es conveniente limitar el número de donaciones precautoriamente, ya que la "poliovulación" -la obtención de más de un óvulo maduro como consecuencia de la administración de hormonas ováricas- cada tres meses (tiempo mínimo que se deja pasar entre una estimulación y la siguiente) "es mucho [...] para el ovario [...] y para el cuerpo en sí".

Una segunda profesional se expresó en un sentido semejante, aunque evidenciando de forma más clara la falta de estudios locales apropiados para monitorear la salud de las mujeres donantes, especialmente dado el hecho de que en Argentina las donantes tienden a donar más de la cantidad de veces aconsejada, cumpliendo la cuota habilitada en sucesivas clínicas:

Todos los estudios que se realizaron están hechos sobre donantes de hace 20 años, 10 años. Lo que les pase a las chicas que están donando ahora nadie lo sabe. Las donantes de ahora no donan como las chicas de antes. Donan más, todo está mucho más repartido. (Ginecóloga 1)

Sin embargo, estos testimonios que tematizan el potencial riesgo para la salud de las mujeres que donan óvulos a través 
de su "trabajo clínico"(11) son minoritarios en relación con aquellas argumentaciones que, como la citada en el apartado anterior, hablan de la necesidad de limitar la cantidad de donaciones de una misma donante debido a la posibilidad de consanguineidad, o "riesgo genético". Los siguientes diálogos ejemplifican cómo, al hablar de riesgo, es el riesgo de endogamia el que predomina en el discurso de los profesionales (especialmente los médicos varones):

La Sociedad [SAMER] hizo una especie de recomendaciones que tienen en cuenta la epidemiología y hacen que cuando en el mismo núcleo poblacional ya una mujer dio un embarazo por millón de habitantes hay que descartar [sic] la donante (lo mismo se hace con los donantes de semen) para evitar la endogamia, porque empieza a aumentar la probabilidad de endogamia [...] [cuando las mismas donantes circulan por varios centros] empieza a aumentar la endogamia, y la endogamia no es buena para el género. Es perjudicial para el género. La endogamia hace que se perpetúen muchos de los caracteres pero también los que no sirven, ¿me explico? (Ginecólogo 4)

¿Puede una donante donar in eternum? No [Enfático], porque según la OMS [Organización Mundial de la Salud] en una ciudad con una población dada solo se puede obtener con donación de gametas $x$ cantidad de hijos, es una fórmula, que está, creo que está en algún libro, creo que está en el manual de semen de la OMS. Una fórmula en la cual un [sic] donante de gametas varón o mujer puede tener hasta $x$ cantidad de embarazos. ¿Por qué? Porque a partir de esa cantidad de embarazos empieza a existir riesgo de consanguineidad. (Ginecólogo 3)

En este sentido, la mayor resonancia clínica del riesgo de consanguineidad (en oposición al riesgo para las mujeres donantes) da cuenta de una ambivalencia respecto de los posibles riesgos para la salud de las mujeres que donan óvulos a una clínica de fertilidad. En efecto, si bien algunas (en concreto, dos) profesionales mujeres ponen de manifiesto la potencialidad de los riesgos ocasionados a las donantes de óvulos, especialmente si estas donan asiduamente, el discurso predominante es el de la prevención del riesgo de endogamia, una consideración del riesgo que no toma en cuenta la especificidad de la donación ovárica, su carácter quirúrgico, y el potencial riesgo que implica de contraer alguna forma de cáncer, de tener una reducción en la fertilidad, o de contraer el síndrome de hiperestimulación ovárica (SHO). Esta desconsideración es también observada en el hecho de citar un "manual de semen" como origen de la medida. En este sentido, como sugieren Cooper y Waldby ${ }^{(11)}$, el trabajo clínico de las donantes de óvulos en el tratamiento clínico de la fertilidad ocasiona riesgos específicos que no son adecuadamente monitoreados, pese a la provisión de medidas para controlarlos.

\section{"Lo que pase primero": el azaroso control del riesgo}

Según los párrafos precedentes, durante los tratamientos de fertilidad se intenta controlar simultáneamente dos riesgos distintos. Por un lado, se apunta a regular el riesgo de pérdida de variabilidad biológica, por el otro (aunque en menor medida) se busca administrar el riesgo para la donante. En efecto, si por una parte existen medidas que -expresadas en términos de cantidad de donaciones, embarazos o nacimientos por cantidad de habitantes- se utilizan para controlar el riesgo de consanguineidad, por otra parte, existen medidas expresadas en términos de donaciones, embarazos o nacimientos por donante (como "8 donaciones por donante", "8 embarazos por donante", etc.) que apuntan a monitorear el riesgo para la salud de las mujeres.

Sin embargo, en la práctica resulta difícil monitorearestos dos riesgos simultáneamente. 
Por lo tanto, ¿cómo se aplican concretamente medidas tan disímiles? ¿En qué momento y bajo qué criterios se decide qué medida utilizar para regular la cantidad de veces que una donante dona a un centro de fertilidad? Los testimonios de los/as profesionales entrevistados/as muestran que no existe una repuesta unívoca para estas preguntas. En efecto, antes que como un criterio objetivo, consensuado y universalmente aplicado que logre unificar el monitoreo de los dos tipos de riesgos (el de consanguineidad a nivel poblacional y el individual de salud para las mujeres), las medidas bioestadísticas que controlan ambos riesgos se usan indistintamente en la práctica médica reproductiva. Algunos/as profesionales mencionan, en efecto, usar la medida poblacional, mientras que otros/as profesionales dicen usar la medida individual. A su vez, ocurre también que la misma persona puede usar ambas medidas dependiendo del caso, y dejar en cierto sentido librada al azar la elección de la medida de control a utilizar, como se mostrará más adelante. Esto implica que, a pesar de la imparcialidad y el carácter aparentemente irrefutable que poseen los números, y de su capacidad para controlar los riesgos racional y exhaustivamente, su uso en el tratamiento reproductivo tiende a imposibilitar, más que a permitir, el apropiado control de los riesgos que emergen, para las poblaciones y las personas involucradas en estos procedimientos, del uso de gametos donados.

Así, el control de los riesgos implicados en el uso de la donación de gametos es inadecuado ya que, en ausencia de una medida única que pueda condensar el monitoreo simultáneo de los dos riesgos (poblacional e individual), se utilizan en la práctica dos medidas combinadas que sirven a propósitos distintos. Como dice una de las profesionales entrevistadas:

A nivel global, hay un límite puesto, un límite de donaciones, que se basa por un lado en el riesgo de consanguineidad y, por otro lado, en el posible riesgo para la donante. Este límite está puesto en seis veces, seis punciones [...] La consanguineidad está dada por una fórmula, no sé cómo se calcula, que es 25 nacidos vivos cada 800.000 habitantes de la misma área [...] Entonces, lo que pase primero, o que haya más de 25 nacidos vivos cada 800.000 habitantes, o que la donante done más de seis veces, paramos ahí. Usualmente es el caso de que donan más de seis veces. (Ginecóloga 1)

Lo que la cita anterior muestra es que, dado que es muy difícil aplicar simultáneamente dos medidas ideadas para controlar tipos de riesgo muy distintos, en la práctica las medidas se seleccionan según "qué es lo que pase primero". Este uso tiene el efecto de producir la percepción organizacional de que "los riesgos" se han controlado, de que se han seguido los protocolos instalados y cumplimentado los procesos previstos; una percepción que no responde, sin embargo, satisfactoriamente a la pregunta respecto de la efectividad de los controles utilizados.

En efecto, ¿qué produce en términos de protección de la salud de las mujeres donantes el uso más o menos aleatorio de dos medidas que limitan, por razones distintas, las veces que una donante puede donar? El riesgo para la salud de las mujeres que se deriva de su participación en calidad de donantes de una donación es inadecuadamente controlado cuando la medida que se aplica es el criterio poblacional de determinada cantidad de donaciones, embarazos o nacimientos para una población dada. En este caso, en tanto esta bioestadística fue matemáticamente derivada teniendo presente la probabilidad de encuentro entre dos "medio-hermanos", su uso abre preguntas respecto de la efectividad con la que puede controlar el riesgo para la salud de las mujeres que se origina en este tipo especial de trabajo clínico, en tanto los pocos estudios realizados (en otros países) muestran que hasta seis donaciones por donante (o una medida similar) no afectan la salud de las mujeres (y no cómo afecta la salud de las mujeres el uso de una medida como $25 \mathrm{em}$ barazos cada 700.000 habitantes).

En la sección que sigue se provee otro tipo de argumentos para la consideración de cómo la forma concreta en que se usan 
ciertos mecanismos de control del riesgo en los centros reproductivos no solo no logran evitar su ocurrencia sino que incluso a veces lo multiplican.

\section{REGISTROS CLÍNICOS DE DONACIÓN}

En este apartado se analiza el uso de registros clínicos de donación para el monitoreo de la cantidad de veces que una donante aporta sus óvulos a un tratamiento reproductivo. Al igual que las medidas bioestadísticas, los registros se utilizan para regular la cantidad de veces que una donante dona sus óvulos, con el objetivo de reducir tanto la probabilidad de riesgo genético como para la salud de las mujeres. A diferencia de las medidas bioestadísticas, sin embargo, la forma de operar de los registros es a través de una "memorialización" de las actividades clínicas, consignando lo que se hizo (la cantidad de veces que una mujer donó), con el objetivo de establecer, en futuras ocasiones, si una donante puede o no continuar donando.

En general, los y las profesionales se muestran muy interesados en la creación y utilización de este tipo de registros, elogiando su efectividad para el control de los riesgos. Sin embargo, hasta la fecha, en Argentina solo se utilizan registros intraclínicos de donación, mientras que no ha sido posible crear un registro colectivo que reúna la información de todas las clínicas ${ }^{[m]}$. Esto sería fundamental, dada la conocida "circulación" de donantes entre clínicas diversas, dando lugar a la superación de las cuotas de donación por donante previstas por las medidas bioestadísticas. Si bien las clínicas tienden a controlar hasta cierto punto, como se mostró anteriormente, cuántas veces dona una donante, las clínicas no tienen forma de confirmar si esa misma donante donó o donará la misma cuota permitida en otras clínicas de fertilidad. Tal situación apunta a la heterogeneidad de racionalidades (principalmente éticas y económicas) que toman parte en la organización de los servicios de donación de gametos, en tanto es precisamente la impronta económica del pago de gametos y de la necesidad clínica de "contar" con un pool semiestable de donantes, la que colisiona con el ímpetu ético de proteger la salud de las mujeres donantes. Por ejemplo, un profesional explicó:

\begin{abstract}
Para que te des una idea, tuve esta reunión en la Asociación [Reproductiva Argentina] y fui con dos amigos. En el camino me contaron que, son parte de SAMER, me contaron que dos o tres centros se juntaron y dijeron: "a ver, vamos a ver, traeme diez donantes, registros de diez donantes, hagámoslo", y en una de las clínicas había una donante que había donado quince veces, iquince! ¡Imaginate la cantidad de embarazos que ha dado en esa clínica, más los que ha dado en otras clínicas...! Y yo no puedo estar llamando "che, [nombre de doctor] tenés una donante [que se Ilama X]. Sería un lío, porque tendría que llamar a treinta clínicas... (Ginecólogo 3)
\end{abstract}

Como es evidente en la cita anterior, si bien se considera muy significativa la creación del registro colectivo de clínicas, hasta tanto este no exista, los centros se ven imposibilitados de controlar el cumplimiento de las cuotas más allá de los controles ejercidos dentro de la clínica. De esta forma, si bien existe un mecanismo sociotécnico -el registro clínico- que permite controlar (hasta cierto punto, según se verá en el párrafo que sigue) cuántas veces dona cada donante en una clínica, la falta de un registro colectivo que aúne información de todas las clínicas que operan en un área geográfica determinada disminuye la eficacia de esta forma de control. Por esta razón, la falta de acciones -estatales y/o privadas- para crear efectivamente el registro colectivo supone la ausencia de mecanismos que regulen de forma adecuada el riesgo potencial sobre la salud de las mujeres, en tanto la limitación que se realiza dentro de cada clínica a la cantidad de veces que una mujer dona, no implica que esta mujer no done sus óvulos a otro(s) centro(s) la misma cantidad de veces, 
multiplicando su exposición a los riesgos de la donación (tal vez sin saberlo, si no ha sido adecuadamente informada de ellos $\left.{ }^{[n]}\right)$ :

Una misma donante dona acá x cantidad de veces, y después se va a otro centro [...] Nosotros tenemos donación exclusiva, o sea que todos los óvulos que se recuperan de una donante son para la receptora, pero yo no te puedo asegurar que esa misma donante [no] vaya a otro instituto y done. En realidad uno no está persiguiendo a las donantes. (Ginecóloga 7)

Nosotros exigimos que hay un tope de hasta seis veces que se puede donar, pero la paciente que donó seis veces acá, donó seis veces en [nombre de instituto de fertilidad], seis veces en [nombre de instituto de fertilidad]. (Ginecóloga 2)

Por otro lado, la forma concreta en la cual los registros son utilizados dentro de la clínica implica que la regulación que estos proponen o ejemplifican no siempre sea efectiva. Esto es, si bien los/as profesionales entrevistados/as por parte de centros de fertilidad relataron en la mayoría de los casos contar con el registro correspondiente, algunos testimonios muestran que el registro no siempre es utilizado según su función prevista. Una profesional comentó por ejemplo:

Entrevistada: De todas maneras una donante no debería donar muchas veces Entrevistadora: ¿Pero eso se cumple? Entrevistada: [Silencio]... Qué se yo... trata de cumplirse [...]

Entrevistadora: ¿Los centros en general tienen registros, tipo "esta donante es la última vez que dona, por ejemplo? Entrevistada: Sí, "esta donante no puede donar más"... La realidad es que hay donantes que son preferidas, "ay, viene fulana de tal", sí porque sabés que tiene lindos óvulos, que en general embaraza, la ovodonación tiene muy buena tasa de éxito. (Embrióloga 1)
Este testimonio indica que si bien existe el registro clínico que estipula si una donante puede o no volver a donar, "la realidad" del centro de fertilidad es que "hay donantes que son preferidas", aquellas cuyos óvulos son "lindos" y que en general logran embarazar. Esta racionalidad alternativa, según la cual se busca la máxima productividad de los óvulos antes que la prevención del potencial riesgo para la salud de las donantes, supone que aquellas donantes con "lindos" óvulos se vean expuestas a un aumento de la probabilidad de su riesgo, en tanto sus óvulos son más requeridos y, en forma de excepción a la norma, se les permite donar una mayor cantidad de veces.

\section{CONCLUSIONES}

Este trabajo analizó el uso de dos dispositivos sociotécnicos (medidas bioestadísticas y registros clínicos de donación) para la regulación de dos riesgos que emergen, en la visión médica reproductiva, del uso de gametos (óvulos) donados. Estos riesgos son la probabilidad de que personas procreadas a partir de la misma donante "se encuentren y se casen" en el futuro, así como la posibilidad de que la salud de las mujeres donantes se vea afectada por el hecho de donar. En cuanto a las medidas bioestadísticas, este artículo mostró que si bien la retórica sobre la importancia de la variación biológica es ubicua en la medicina reproductiva argentina, promoviendo el entendimiento generalizado de que es importante prevenir el riesgo de encuentro de dos "medio-hermanos", existen también otras preocupaciones, menos explícitas pero, sin embargo, también presentes, entre los profesionales del campo. Estas preocupaciones son, efectivamente, la posibilidad de dañar la salud de las mujeres donantes, en especial, en lo relativo a su probabilidad de contraer cáncer y a su fertilidad futura. La presencia de estos dos riesgos incita a la utilización de dos tipos de medidas de control distintas: una medida poblacional, matemáticamente derivada y abstracta, que regula la probabilidad 
de encuentro de personas con los mismos ancestros, y una medida individual, empíricamente derivada de unos pocos estudios en mujeres concretas, que indica un límite de donaciones hasta el cual se ha mostrado que no existen mayores riesgos para las mujeres. En la práctica médica, sin embargo, resulta muy difícil utilizar estas medidas de forma combinada. Esto implica que ambas medidas son aleatoriamente utilizadas ("según qué pase primero"). Sin embargo, ya que cada medida intenta controlar un tipo de riesgo distinto, y dada la imposibilidad de regular dos riesgos simultáneamente, el resultado es que en ocasiones la medida poblacional es utilizada para controlar el riesgo para la salud de las mujeres, y la medida individual utilizada para regular el riesgo genético. Así, las medidas poblacionales bioestadísticas y abstractas derivadas de una probabilidad matemática, escindidas de las condiciones locales concretas que contextualizan su uso (dispersión geográfica, grado de parentesco entre individuos de una población, historia poblacional o sanitaria), así como de su especificidad sexual (al ser formuladas indistintamente tanto para la donación de esperma como de óvulos), son utilizadas para prevenir el riesgo para la salud de las mujeres concretas que donan con su trabajo clínico ${ }^{(11)}$ sus óvulos a los centros reproductivos. De la misma manera, aunque derivadas empíricamente, las medidas individuales que regulan el riesgo para la salud de las mujeres se tornan abstractas y separadas de la realidad de las mujeres donantes, en tanto provienen de estudios realizados en otros contextos regionales distintos de la Argentina.

En cuanto a la utilización de los registros clínicos de donación, este trabajo mostró que si bien la mayoría de las clínicas los implementa como medida de control, la ausencia de sinergias que garanticen la construcción de un registro interclínico que centralice la información de todas las clínicas implica que no se regule adecuadamente el riesgo para la salud de las mujeres. Así, mientras existen registros en las clínicas individuales que permiten establecer si una donante puede o no volver a donar, la ausencia de un registro central incita a la circulación de donantes por diversas clínicas, testimoniada muy frecuentemente por los/as profesionales entrevistados/as, en las que cumplen sus diferentes cuotas de donación. Como es evidente, la carencia de una coordinación central es inadecuada para controlar apropiadamente el riesgo para la salud de las mujeres donantes, un riesgo que como se mostró se ve incrementado por la forma particular en la cual se utilizan de hecho los registros clínicos, es decir, a través de excepciones que favorecen la donación por parte de ciertas donantes (con óvulos "lindos") más allá de las veces que sea conveniente donar. Resulta fundamental considerar, asimismo, la potencial falta de información con que las donantes deciden donar a diversos centros reproductivos, en tanto la ausencia de evidencia médica respecto de una asociación entre donación de óvulos y cáncer o baja de la fertilidad podría estar afectando la calidad y tipo de información suministrada a las donantes sobre este punto.

Los análisis así propuestos aportan una contribución para reflexionar en qué medida no se trata de la ausencia de mecanismos de monitoreo y prevención de la salud de las mujeres en los centro reproductivos, sino de la forma en la cual la implementación concreta de tales mecanismos perjudica las posibilidades que estos tienen de realizar su tarea de control, a la vez que genera la ficción corporativa de que, como esos mecanismos se han implementado, los riesgos han sido adecuadamente monitoreados. Estos hallazgos abren preguntas éticas más amplias respecto de la participación de sujetos de experimentación y donación en la bioeconomía contemporánea, señalando la ocurrencia de riesgos específicos para estos tipos de trabajo clínico, así como la necesidad de controlarlos adecuadamente.

Asimismo, los resultados aquí presentados apuntan en la misma dirección que la tendencia de los análisis ya ofrecidos para otras regiones respecto de la importancia del aspecto biológico en los modos autóctonos de comprensión del parentesco. Así, como señala este texto, es la preocupación 
respecto de la posible unión futura de "medio-hermanos", entendidos como aquellos/as que comparten un progenitor genético, lo que constituye el foco de las actividades de control del riesgo de la clínica de fertilidad. Tales entendimientos, que sugieren que en Argentina el parentesco es entendido como fuertemente determinado por el componente genético, al menos entre los/as profesionales entrevistados/ as, parecieran ser coextensivon a un aspecto moral: aquellos/as que comparten genes no deben unirse nuevamente. Así, se confirma lo planteado por Bestard ${ }^{(30)}$ : en la clínica reproductiva, los aspectos sociales y biológicos son coproducidos, en la medida de que controlar el riesgo genético supone también instalar la precaución contra riesgos morales.

\section{AGRADECIMIENTOS}

La autora desea agradecer el generoso apoyo de las siguientes instituciones y esquemas de financiación para la realización del presente artículo: Alßan Programme (Unión Europea, proyecto número E07D403209AR); Overseas Research Student Award Scheme (Reino Unido); Central Research Fund (University of London, Reino Unido); Allan and Nesta Ferguson Charitable Trust (Reino Unido), Foundation for the Sociology of Health and Illness (Reino Unido). Asimismo, desea expresar su gratitud hacia los y las profesionales médicos que prestaron su tiempo para la realización de las entrevistas. Por último, agradece la lectura de los miembros del Grupo de Estudios sobre Sexualidades (GES) de la Universidad de Buenos Aires.

\section{REFERENCIAS BIBLIOGRÁFICAS}

1. Ariza L. Gestión poblacional del parentesco y normatividad: la producción de variabilidad biológica en el intercambio de gametas de la reproducción asistida. En: Jones D, Figari C, Barrón López S, (ed.). La producción de la sexualidad: políticas y regulaciones sexuales en Argentina. Buenos Aires: Biblos; 2012. p. 127-146.

2. Ariza L. "No pagarás": el consentimiento informado como productor de solidaridad en la medicina reproductiva. Ciencia, Docencia y Tecnología. 2016;27(52):87-115.

3. Reproducción asistida: deudas de una ley que cumplió un año. Infobae [Internet].12 jun 2014 [citado 4 oct 2014]. Disponible en: http://goo.gl/ yXJILR.

4. González-Santos SP. Specialization in action: The genealogy and current state of assisted reproduction. Bulletin of Science, Technology \& Society. 2014;34(1-2):33-42.
5. Corea G. The mother machine: Reproductive technologies from artificial insemination to artificial wombs. New York: Harper \& Row; 1985.

6. Oakley A. From walking wombs to test-tube babies. En: Stanworth MD, (ed.). Reproductive technologies: Gender, motherhood and medicine. Cambridge: Polity; 1987. p. 36-56.

7. Sandelowski M. Infertility and imperiled sisterhood. Feminist Studies. 1990;16(1):33-51.

8. Procrearte. Ovodonación [Internet]. Buenos Aires: Procrearte [citado 15 oct 2015]. Disponible en: http://goo.gl/f3IXzn.

9. Roberts C, Throsby K. Paid to share: IVF patients, eggs and stem cell research. Social Science \& Medicine. 2007;66:159-169.

10. American Society for Reproductive Medicine. Síndrome de hiperestimulación ovárica (SHO) [lnternet]. Birmingham: ASRM; 2015 [citado 19 oct 2015]. Disponible en: https://goo.gl/r9YCSN.

11. Cooper M, Waldby C. Clinical labor: Tisuse donors and research subjects in the global bioeconomy. Durham: Duke University Press; 2014.

12. Sommer S. New reproductive technologies: A report from Argentina. Issues in Reproductive and Genetic Engineering. 1991;4(1):41-43.

13. Sommer S. Nuevas formas de procreación. En: Scavone L, (ed.). Género y salud reproductiva en América Latina. Cartago: Libro Universitario Regional; 1999. p. 308-332.

14. Luna F. Assisted reproductive technology in Latin America: Some ethical and sociocultural issues. En: Vayena E, Rowe PJ, Griffin PD, (ed.). Current practices and controversies in assisted reproduction. Geneva: WHO; 2002. p. 31-40. 
15. Luna F. Bioethics and vulnerability: A Latin American view. Amsterdam: Rodopi; 2006.

16. Luna F. Infertilidad en Latinoamérica: En busca de un nuevo modelo. Revista de Bioética y Derecho. 2013;28:33-47.

17. Garay R. El destino de ser madres: la ideología de la maternidad como soporte discursivo de las nuevas tecnologías reproductivas. En: Tarducci $M$, (ed.). Maternidades en el siglo XXI. Buenos Aires: Espacio Editorial; 2008. p. 29-56.

18. Raspberry KA. Conflicted conceptions: An ethnography of assisted reproduction practices in Argentina. [Dissertation for the degree of Doctor of Philosophy]. Center for Genomics and Society, University of North Carolina at Chapel Hill; 2007.

19. Kemelmajer de Carlucci A, Herrera M, Lamm E. La reproducción médicamente asistida: Mérito, oportunidad y conveniencia de su regulación. La Ley Uruguay. 2011;(10):1305-1317.

20. Calise SG. El derecho observando a los embriones: el caso argentino. Nómadas: Revista Crítica de Ciencias Sociales y Jurídicas. 2011;(29):303-323.

21. Lloveras N, Sapena J. El diagnóstico genético preimplantacional. Revista de Bioética y Derecho. 2010;(18):10-16.

22. Cuberli M, Lois M, Palopoli A. Cruces y tensiones discursivas en salud sexual y reproductiva: test de VIH, anticoncepción de emergencia, aborto y fertilización asistida. En: Petracci $M$, (ed.). Derechos sexuales y reproductivos: teoría, política y espacio público. Buenos Aires: Teseo; 2011. p. 133-215.

23. Straw C, Petracci M. Sistemas de salud, trayectorias recorridas en reproducción asistida y demandas al Estado: vinculaciones conflictivas para las mujeres de sectores populares del Área Metropolitana de Buenos Aires. Eä Revista de Humanidades Médicas y Estudios Sociales de la Ciencia y la Tecnología. 2012;4(1):1-28.

24. Bacin G, Gemetro F. Comaternidad: Experiencias, autodefiniciones y derechos. En: Felitti $\mathrm{K}$, (ed.). Madre no hay una sola: Experiencias de maternidad en la Argentina actual. Buenos Aires: Ciccus; 2011. p. 93-109.

25. Ariza L, Libson M. Biología, maternidad y derechos: Experiencias de mujeres heterosexuales y mujeres lesbianas con la procreación asistida. En: Geldstein RN, Schufer ML, (ed.). Problemas actuales de salud reproductiva, familia, género y sexualidad: La investigación social de la diversidad. Buenos Aires: UNFPA/Biblos; 2011. p. 317-351

26. Ariza L. La procreación como evento natural o tecnológico: repertorios decisorios acerca del recurso a la reproducción asistida en parejas infértiles de Buenos Aires. Eä Revista de Humanidades Médicas y Estudios Sociales de la Ciencia y la Tecnología. 2010;2(1):1-46.

27. Ariza L. Keeping up appearances in the Argentine fertility clinic: Making kinship visible through race in donor conception. Tecnoscienza: Italian Journal of Science and Technology Studies. 2015;6(1):5-31.

28. Ariza L. "Dar vida": en torno al derecho a la cobertura médica del tratamiento de la infertilidad. En: Felitti K, (ed.). Madre no hay una sola: Experiencias de maternidad en la Argentina actual. Buenos Aires: Ciccus; 2011. p. 73-91.

29. Puerto JJ. La consideración de los nuevos derechos humanos en la legislación sobre reproducción asistida. Acta Bioethica. 2000;VI(1):127-140.

30. Bestard J. Los hechos de la reproducción asistida: entre el esencialismo biológico y el constructivismo social. Revista de Antropología Social. 2009;18:83-95.

31. Jarufe Contreras D. Tratamiento legal de las filiaciones no biológicas en el ordenamiento jurídico español: adopción versus técnicas de reproducción asistida. Madrid: Dykinson; 2013.

32. Farnós Amorós E. European Society of Human Reproduction and Embriology 26th Annual Meeting. InDred: Revista para el Análisis del Derecho. 2010;3:2-17.

33. Rosset GM, Jenaro Río C, Antequera Jurado R, Gómez Sánchez Y. La psicología de la reproducción: la necesidad del psicólogo en las unidades de reproducción humana. Clínica y Salud. 2009;20(1):79-90.

34. Fernández Jimeno N. Desafiando la institución de la maternidad: reapropiaciones subversivas de las tecnologías de reproducción asistida (TRA). Revista Iberoamericana de Ciencia y Tecnología. 2016;31(11):119-146.

35. Herrera F, Teitelboim B, Zegers Hochschild F. Tipologías y argumentos en torno a las técnicas de reproducción asistida en habitantes de Santiago de Chile. Revista Médica de Chile. 2015;143:1527-1532.

36. Solano Castillo P. El derecho a la salud y la reproducción asistida. Medicina Legal de Costa Rica. 2003;20(1):15-27. 
37. Montes Guevara GE. Bioética y técnicas de reproducción asistida. Revista de Ciencias Administrativas y Financieras de la Seguridad Social. 2004;20(1):71-78.

38. Escobar Fornos I. Derecho a la reproducción humana (inseminación y fecundación in vitro). Cuestiones Constitucionales. 2007;16:137-158.

39. Córdoba Palacio R. Consideraciones biológicas y antropológicas acerca del embrión y la reproducción asistida. Persona y Bioética. 2007;28(1):54-63.

40. Correa FJL. El diálogo bioético en las técnicas de reproducción asistida. Acta Bioethica. 2009;13(2):161-167.

41. Gómez de la Torre M. Técnicas de reproducción humana asistida, desafíos del siglo XXI: una mirada transdisciplinaria. Santiago: Abeledo Perrot; Thomson Reuters: 2013.

42. Zegers Hochschild F, Salas Ibarra S. Bioética, reproducción y familia. Santiago: Ediciones UDP; 2014.

43. Bernal Crespo JS. Reproducción asistida y filiación: Tres casos. Opinión Jurídica. 2013;12(24): 135-150.

44. Barcia R, Riveros C. El derecho al conocimiento del origen biológico como un derecho fundamental de naturaleza civil-constitucional derivado del derecho a la identidad y de la dignidad humana. En: Gómez de La Torre M, (ed.). Técnicas de reproducción humana asistida, desafíos del siglo XXI: una mirada transdisciplinaria. Santiago: Abeledo Perrot; Thomson Reuters; p. 189-222.

45. Gómez de la Torre M. El sistema filiativo chileno: Filiación biológica, por técnicas de reproducción asistida y por adopción. Santiago: Editorial Jurídica de Chile; 2007.

46. Vasconcelos C, Lustosa C, Meirelles AT, Vieira Aranha A, Garrafa V. Direito ao conhecimento da origem biológica na reprodução humana assistida: reflexões bioéticas e jurídicas. Revista Bioética. 2014;22(3):509-518.

47. Albertoni Vazzaco A, Olivieri Valelongo P, Dieb Miziara I, Parente Barbosa C. Entendimento do consentimento livremente esclarecido na reprodução assistida. Revista Bioética. 2014;22(1):134-144.

48. Roberts E. Extra embryos: The ethics of cryopreservation in Ecuador and elsewhere. American Ethnologist. 2007;34(1):181-199.
49. Escalante Barboza K. Métodos de reproducción asistida: aspectos psicológicos. Medicina Legal de Costa Rica. 2003;20(1):5-13.

50. Lanius M, Souza ELA. Reprodução assistida: os impasses do desejo. Revista Latinoamericana de Psicopatologia Fundamental. 2010;13(1):53-70.

51. Romero Márquez NR. Representación social de las técnicas de reproducción asistida. Revista de la Facultad de Medicina. 2002;25(2):231-236.

52. Biagioli M. Introduction: Science studies and its disciplinary predicament. En: Biagioli M, (ed.). The science studies reader. New York: Routledge; 1999. p. xi-xviii.

53. HackettEJ, Amsterdamska O, Lynch M, Wajcman J. Introduction. En: Hackett EJ, Amsterdamska O, Lynch M, Wajcman J, (ed.). The handbook of science and technology studies. 3rd ed. Cambridge: MIT Press; 2008. p. 1-7.

54. Lynch M. Ideas and perspectives. En: Hackett EJ, Amsterdamska O, Lynch M, Wajcman J, (ed.). The handbook of science and technology studies. 3rd ed. Cambridge: MIT Press; 2008. p. 9-11.

55. Latour B, Woolgar S. Laboratory Life: The Construction of scientific facts. 2nd ed. Princeton: Princeton University Press; 1986.

56. Law J. Actor network theory and material semiotics [Internet] 25 abr 2007 [citado 10 oct 2015]. Disponible en: http://goo.gl/d4U5f3.

57. Cressman D. A brief overview of actor-network theory: Punctualization, heterogeneous engineering \& translation [Internet]. 2009 [citado 10 oct 2015]. Disponible en: http://goo.gl/UNMkDo.

58. Latour B. Reensamblar lo social: Una introducción a la teoría del actor-red. Buenos Aires: Manantial; 2008.

59. Foucault M. Discipline and punish: The birth of the prison. Londres: Allen Lane; 1977.

60. Mol A. The body multiple: Ontology in medical practice. Durham: Duke University Press; 2002.

61. Ariza L. The normativity of nature: Morality, variability and kinship in the gamete exchange. Tesis de Doctorado, Department of Sociology, Goldsmiths, University of London. 2013.

62. Ariza L. Fotografías, registros médicos y la producción material del parentesco: acerca de la coordinación fenotípica en la reproducción asistida en Argentina. En: Cepeda A, Rustoyburu, C, (eds.). 
De las hormonas sexuadas al Viagra. Ciencia, Medicina y Sexualidad en Argentina y Brasil. Mar del Plata: EUDEM; 2014. p. 173-206.

63. Darwin C. On the origin of species. Oxford: Oxford University Press; 2008.

64. ASRM. Repetitive oocyte donation. Fertility \& Sterility. 2006;86(Suppl 4):S216-S217.

65. Does test tube baby treatment increase cancer risk? [Internet] Cancer Research UK [citado 10 oct 2015]. Disponible en: http://goo.gl/8aLDBx.

66. National Institute for Clinical Excellence. Fertility assessment and treatment for people with fertility problems [Internet]. London: NICE; 2004 [citado 10 oct 2015]. Disponible en: http://goo.gl/dXiEM3.

\section{NOTAS FINALES}

[a] El resultado final de esa investigación se plasmó en la tesis de doctorado titulada "The normativity of nature: Morality, variability and kinship in the gamete exchange" (Goldsmiths, University of London). Un análisis distinto del uso de medidas bioestadísticas, como las examinadas en este artículo, fue publicado bajo el título "Gestión poblacional del parentesco y normatividad: la producción de variabilidad biológica en el intercambio de gametas de la reproducción asistida"(1).

[b] A fines prácticos, en este artículo se habla de "donación" de óvulos. Sin embargo, el término debe ser críticamente desnaturalizado, en tanto en Argentina el intercambio de óvulos es pago, y remunerado con altos montos. Para un análisis de los dispositivos sociotécnicos que producen la donación como tal, ver Ariza ${ }^{(2)}$.

[c] Según la American Society for Reproductive Medicine (ASRM) "El síndrome de hiperestimulación ovárica $(\mathrm{SHO})$ es una respuesta excesiva a los medicamentos que se utilizan para hacer crecer los óvulos (especialmente a las gonadotropinas inyectables)". El SHO ocasiona la presencia de muchos folículos en crecimiento, lo que conduce a una filtración de líquido al abdomen, provocando distención, náuseas, e hinchazón. En los cuadros graves, se pueden presentar coágulos de sangre, dificultad respiratoria, dolor abdominal, deshidratación y vómitos. En raras ocasiones, el síndrome puede ser mortal ${ }^{(10)}$.

[d] Cooper y Waldby ${ }^{(11)}$ definen "trabajo clínico" como un tipo específico de trabajo corporal (embodied) realizado por determinadas personas (gestante subrogada, proveedores/as de tejidos y partes corporales, participantes de estudios clínicos) para la industria biomédica posfordista. Según estas autoras, la biología in vivo de ciertos sujetos humanos es inscripta en el proceso de trabajo contemporáneo a través de la transferencia de tejidos o la producción experimental de datos. Estas formas de trabajo corporal son crecientemente centrales para la creación de valor de la economía posfordista. En particular, la expansión de los mercados ligados a la reproducción asistida demanda cada vez más proveedores tercerizados (como vendedores/as de gametos y gestantes subrogadas) para satisfacer la creciente demanda de servicios reproductivos. En este artículo, se considera que las donantes de óvulos están comprendidas dentro de esta definición de "trabajo clínico".

[e] En este episodio, el físico y matemático Alan Sokal presentó un artículo a la revista Social Text, el cual era intencionadamente fraudulento y hacía uso de una serie de teorías genéricamente relacionadas con el posmodernismo, intentando mostrar la ausencia de razonabilidad de estas. El artículo fue efectivamente publicado en la revista, con lo que se generó el debate sobre el argumento propuesto por Sokal.

[f] Del original "Actor-network theory is a disparate family of material-semiotic tools, sensibilities and methods of analysis that treat everything in the social and natural worlds as a continuously generated effect of the webs of relations within which they are located. It assumes that nothing has reality or form outside the enactment of those relations. Its studies explore and characterise the webs and the practices that carry them. Like other material-semiotic approaches, the actornetwork approach thus describes the enactment of materially and discursively heterogeneous relations that produce and reshuffle all kinds of actors including objects, subjects, human beings, machines, animals, 'nature', ideas, organisations, inequalities, scale and sizes, and geographical arrangements." ${ }^{\prime(56 \text { p.2) }}$

[g] Del original "...instead of studying these topics by teasing out what doctors know or what happens to patient's self-knowledge, I have analyzed the knowledge incorporated in practices [...] does not reside in subjects alone, but also in buildings, knives, dyes, desks [...] the material organization of medical practice shapes the reality of disease." ${ }^{\prime \prime}(60.48)$

[h] Del original "about what they do and about the events that happen to them, rather than about their thinking." ${ }^{\prime \prime 0 ~ p .16)}$

[i] Del original "requires an investigation into clinical procedures and apparatuses rather than into the minds and cognitive operations of physicians." 
[j] En un texto anterior ${ }^{(1)}$ he analizado la significativa variación en la forma en la cual los ratios son citados y utilizados en los centros de fertilidad.

[k] Del original "It is difficult to provide a precise number of times that a given donor can be used because one must take into consideration the population base from which the donor is selected and the geographic area that may be served by a given donor. It has been suggested that in a population of 800,000, limiting a single donor to no more than 25 births would avoid any significant increased risk of inadvertent consanguineous conception. This suggestion may require modification if the population using donor insemination represents an isolated subgroup or if the specimens are distributed over a wide geographic area." (64)

[l] En principio, la (escasa) investigación realizada hasta la fecha en países centrales permite concluir que no se ha demostrado una asociación entre la ingesta de hormonas sexuales y el cáncer. Sin embargo, los estudios al respecto están todavía en curso y han dado resultados no conclusivos. Cancer Research UK cita, por ejemplo, una serie de estudios daneses, holandeses, australianos y británicos que han demostrado la ausencia de asociación entre cáncer de ovario y mama y la ingesta de hormonas reproductivas ${ }^{(65)}$. Una revisión del año 2006 de las guías de donación de la ASRM establece que no hay asociación entre agentes de estímulo a la ovulación y el cáncer de ovario, aunque aclara que "una conclusión definitiva todavía requiere de mayores estudios"(64 p.S216). Un reporte de 2004 del National Institute for Clinical
Excellence (National Health Service, UK) indica, sin embargo, que "las mujeres a las que se les ofrece inducción de la ovulación deben ser informadas de que una posible asociación entre terapias de inducción de la ovulación y el cáncer de ovario permanece incierta" ${ }^{\prime \prime 66 ~ p .34)}$. La potencial reducción en la fertilidad de la donante es, sin embargo, un tema distinto. Las guías de 2006 de la ASRM establecen por ejemplo que "actualmente no se conoce si la aspiración folicular reiterada podría afectar la fertilidad futura de la donante"(64 p.S216).

[m] Cabe notar que, si bien es discutida como una necesidad del campo reproductivo desde hace varios años, la creación de un registro único de bancos de gametos y/o embriones está comandada por la Ley de Reproducción Médicamente Asistida sancionada en junio de 2013. Sin embargo, tal registro todavía no se ha creado.

[n] Este punto debería ser mejor investigado en sucesivos estudios. En efecto, en tanto existe el consenso médico -basado en un pequeño grupo de estudios realizados hace ya muchos años- de que donar hasta seis $u$ ocho veces no daña la salud de las mujeres, el mensaje que se transmite a las potenciales donantes en las reuniones de convocatoria es que "donar no trae riesgos para la salud". Cómo esta información se recibe y reinterpreta, especialmente en el contexto de necesidad económica que marca para muchas mujeres la decisión de donar, supone la posibilidad de que los posibles riesgos para la salud sean desconocidos o ignorados por las mujeres que deciden donar.

\section{FORMA DE CITAR}

Ariza L. Cuerpos abstractos, riesgos concretos: dispositivos clínicos y la salud de las donantes de óvulos en la medicina reproductiva argentina. Salud Colectiva. 2016;12(3):361-382. doi: 10.18294/sc.2016.789

Recibido: 5 de noviembre de 2015 | Versión final: 17 de junio de 2016 | Aprobado: 30 de junio de 2016

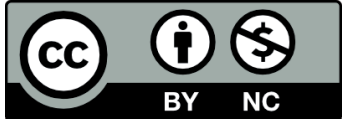

Este obra está bajo una licencia de Creative Commons Reconocimiento-NoComercial 4.0 Internacional. Reconocimiento - Permite copiar, distribuir y comunicar públicamente la obra. A cambio, se debe reconocer y citar al autor original. No Comercial - Esta obra no puede ser utilizada con finalidades comerciales, a menos que se obtenga el permiso.

http://dx.doi.org/10.18294/sc.2016.789 